\title{
XÁC ĐỊNH CÁC THUỘC TÍNH KÌ VỌNG CỦA MỸ PHẨM CHĂM SÓC DA TRÊN THİ TRƯỜNG THÀNH PHỐ HỒ CHÍ MINH
}

\begin{abstract}
Đặng Thị Kiều Nguyễn Thị Thu Sương², Trương Vă

TÓM TẮT

Muc tiêu: Xác đinh các thuôc tính kì vọng đối với mỹ phẩm chăm sóc da của người tiêu dùng thành phố Hồ Chí Minh trong năm 2020. Đối tượng và phương pháp nghiên cứu: Mô tả cắt ngang định tính (phỏng vấn) và mô tả cắt ngang định lượng (phát phiếu khảo sát, phân tích kết hợp) các thuộc tính và mức độ thuộc tính của mỹ phẩm chăm sóc da đối với người tiêu dùng trong thành phố Hồ Chí Minh. Kết quả: Mỹ phẩm chăm sóc da được người tiêu dùng tại thành phố Hồ Chí Minh yêu thích nhất năm 2020 là mỹ phẩm chăm sóc da có xuất xứ từ Hoa Kỳ, thành phần từ thiên nhiên, có công dụng Chống lão hóa, được bào chế dưới dạng Kem, không chứa Corticoid và có giá bán giao động từ 300.000 đồng đến dưới 500.000 đồng. Kết luận: Nghiên cứu đã tìm ra mỹ phẩm chăm sóc da phù hợp với thị hiếu của người tiêu dùng thành phố Hồ Chí Minh trong năm 2020 và cung cấp thêm thông tin về các nhóm đối tượng tiêu dùng riêng mà dựa trên đó doanh nghiệp có thể xác định những thuộc tính được ưa thích của phân khúc khách hàng mình hướng tới.
\end{abstract}

Tư khóa: mỹ phẩm chăm sóc da, thuộc tính, người tiêu dùng.

\section{SUMMARY \\ DETERMINING TYPES OF SKIN CARE COSMETICS ON THE MARKET HO CHI MINH CITY \\ Objective:. The study was conducted to determine the expected attributes for the skin care cosmetics of consumers in Ho Chi Minh City in 2020. Subjects and Methods: Description of qualitative cross-section (interview) and quantitative cross- section description (issue of survey, combination analysis) of the attributes and attribute level of skin care cosmetics for consumers in Ho Chi Minh City. Results: The expected skin care cosmetic of consumers in Ho Chi Minh City in 2020 is skin care cosmetic originating from the United States, ingredients from nature, with anti-aging effects, formulated under cream form, does not contain corticoid, and has a selling price ranging from 300.000 VND to under 500.000 VND. Conclusion: Research has found skin care cosmetics that suit the trends of consumers in Ho Chi Minh City in 2020 and provide}

${ }^{1}$ Đại học Y Dược Thành Phố Hồ Chí Minh

'Sở Khoa học và Công nghệ Thành Phố Hồ Chí Minh

${ }^{3}$ Công ty Cổ phần Công nghệ ChatBot Việt Nam.

Chịu trách nhiệm chính: Nguyễn Thị Hải Yến

Email: haiyen@ump.edu.vn

Ngày nhận bài: 5.3.2021

Ngày phản biện khoa học: 26.4.2021

Ngày duyệt bài: 10.5.2021 additional information on specific consumer groups from which businesses can identify the preferred attributes of the customer segment that they target

Keywords; skin care cosmetic, attributes, customers

\section{I. ĐẶT VẤN ĐỀ}

Thu nhập của người dân càng ngày càng nâng cao, các nhu câu sinh lý và an toàn cơ bản được thỏa mãn, con người sẽ tiến lên các nấc cao hơn của tháp nhu cầu Maslow ${ }^{(1)}$. Ngoại hình ngày càng được chú trong ở cả hai giới, đi cùng với đó là sự gia tăng về nhu câu làm đẹp nói chung và sử dụng mỹ phẩm nói riêng. Với dân số trên 96 triệu người(2), Việt Nam là một thị trường đây hứa hẹn cho các nhà kinh doanh mỹ phẩm. Quy mô thị trường mỹ phẩm trang điểm là 480 triệu USD và quy mô thị trường mỹ phẩm chăm sóc và làm sạch là 1,87 tỷ USD(3).Thị trường càng tiêm năng thì mức độ cạnh tranh càng cao, đặc biệt là mảng mỹ phẩm chăm sóc da (MPCSD). Theo cổng thông tin quốc gia về đăng ký doanh nghiệp, trên địa bàn thành phố Hồ Chí Minh (TPHCM) có hơn 5.000 doanh nghiêp kinh doanh mỹ phẩm, tuy nhiên các doanh nghiệp Việt Nam chỉ chiếm được $10 \%$ thị phân, $90 \%$ còn lại thuộc về các nhà cung cấp đến từ nước ngoài(4). Việc xác định được sản phẩm mỹ phẩm kỳ vọng của người tiêu dùng là ưu tiên hàng đâu đối với các doanh nghiệp sản xuất và kinh doanh mỹ phẩm trong việc nghiên cứu và phát triển sản phẩm để chiếm lĩnh thị trường. Xuất phát từ những thực tế trên, nghiên cưu: "Xác định các thuộc tính của mỹ phâm chăm sóc da ki vọng trên thi trường thành phố Hồ Chí Minh năm 2020" được thực hiện với muc đích cung cấp thông tin về thị trường mỹ phẩm, đặc biệt là MPCSD, giúp các doanh nghiệp kinh doanh mỹ phẩm chăm sóc da Việt Nam có thêm cơ sở để nghiên cứu và phát triển sản phẩm. Nghiên cứu nhằm mục đích xác định các thuộc tính của MPCSD kì vọng trên thị trường thành phố Hồ Chí Minh năm 2020 từ đó đưa ra sản phẩm mỹ phẩm kỳ vọng của người tiêu dùng.

\section{II. ĐỐI TƯỢNG VÀ PHƯƠNG PHÁP NGHIÊN CỨU}

2.1. Đối tượng nghiên cứu. Các thuộc tính và mức độ thuộc tính của mỹ phẩm chăm sóc da.

\subsection{Phương pháp nghiên cứu}

2.2.1 Thiêt kếnghiên cứu. Nghiên cứu mô 
tả cắt ngang, định tính (phỏng vấn) kết hợp định lượng (phát phiếu khảo sát, phân tích kểt hợp) các thuộc tính và mức độ thuộc tính của MPCSD đối với NTD tại TPHCM.

Thời gian thực hiện nghiên cứu từ tháng 12/2019 đến tháng 9/2020 tại cửa hàng, nhà thuốc có bán MPCSD, phòng khám về da liễu, chuỗi siêu thị chuyên về mỹ phẩm, spa trên địa bàn TPHCM. Quy trình thực hiện nghiên cứu được trình bày cụ thể ở Hình 1.

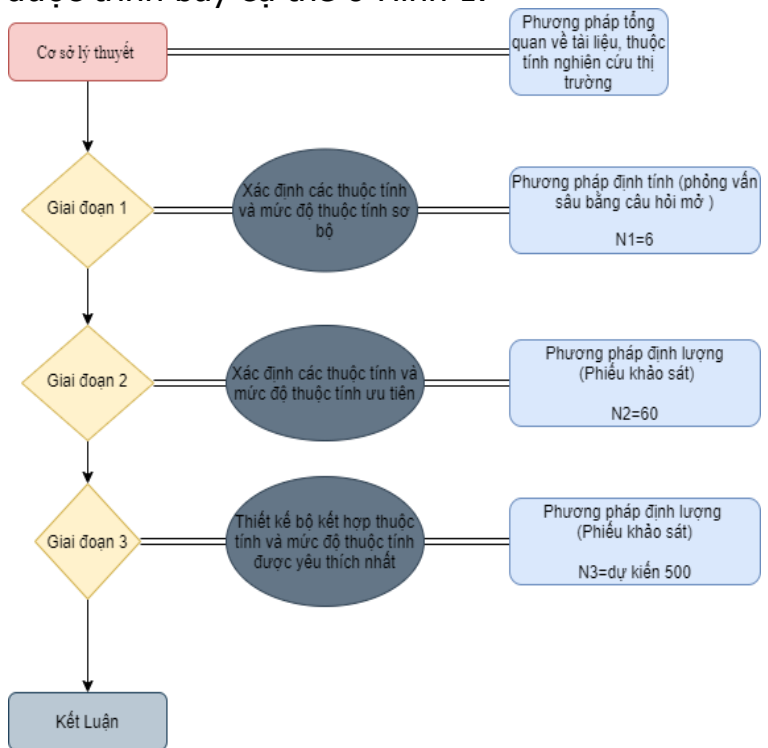

Hình 1. Quy trình thực hiên nghiên cứu

\subsubsection{Phương pháp nghiên cứu}

2.2.2.1. Xác đinh các thuộc tính, mức thuộc tính sơ bộ của mỹ phẩm chăm sóc da. Dựa vào tổng quan lý thuyết để tìm ra các tập hợp thuộc tính mỹ phẩm, tiến hành phỏng vấn 6 chuyển gia về tập hợp thuộc tính mỹ phẩm đã tìm được ở phần tổng quan và dựa vào đó để sửa đổi, bổ sung, hiệu chỉnh lại các thuộc tính và mức độ thuộc tính của sản phẩm mỹ phẩm cho phù hợp.

2.2.2.2. Xây dựng hồ sơ chứa các thuộc tính mỹ phẩm chăm sóc da được người tiêu dùng tại thành phố Hồ Chí Minh ưu tiên lựa chọn. Xây dựng bảng câu hỏi cho phiếu khảo sát

Phát phiếu cho NTD với quy ước cách cho điểm từng mức độ thuộc tính theo thang điểm từ 1 đến 5 với quy ước mức độ quan trọng càng cao thì cho điểm càng cao.

Lọc các phiếu hợp lệ với tiêu chí phiếu hợp lệ là phiếu có nội dung khảo sát được hoàn thành đầy đủ và thỏa mãn câu hỏi record, sau đó nhập liệu bằng phần mềm Microsoft Excel 2016. Bển cạnh đó tiến hành tính phần trăm số phiếu không hợp lệ trên tổng số phiếu khảo sát đã tiến hành, giả sử kết quả thu được là F\%.
Tính toán trị số trung bình các mức độ thuộc tính được người tiêu dùng yêu thích hơn.

Chạy thiết kế trực giao bằng phần mềm SPSS 22 để tìm ra danh sách các bộ kết hợp thuốc tính quan trọng được người tiêu dùng tại thành phố Hồ Chí Minh ưu tiên lựa chọn.

2.2.2.3. Xác định hồ sơ mỹ phẩm chăm sóc da được người tiêu dùng tại thành phố Hồ Chí Minh yêu thích nhất.

Hiệu chỉnh câu hỏi cho phiếu khảo sát và tiến hành tính toán cỡ mẫu với công thức

$$
\mathrm{N3}=\frac{10 \times \text { Tổng tham số }}{1-\mathrm{F} \%}
$$

Trong đó Tổng tham số sẽ bằng tổng các mức độ thuộc tính trừ tổng các thuộc tính và cộng với 1. Ví dụ có 4 thuộc tính mỗi thuộc tính có 3 mức độ thì tổng tham số là $9(4 \times 3-4+1)$. Tỷ số giữa cỡ mẫu và tổng tham số sẽ từ 5 tới 10 .

Sau khi phát phiếu và thu phiếu, tiến hành lọc các phiếu hợp lệ.

Nhập liệu và phân tích bằng phần mềm SPSS 22. Kết quả phân tích bằng phần mềm là giá trị tầm quan trọng của các thuộc tính và điểm sổ tiện ích của các mức độ thuộc tính. Giá trị tầm quan trọng để so sánh độ quan trọng của các thuộc tính. Điểm số tiện ích thể hiện sự yêu thích của người tiêu dùng, bộ kết hợp thuộc tính nào có điểm số tiện ích cao nhất thì được người tiêu dùng yêu thích nhất và dễ dàng thỏa mãn kỳ vọng của người tiêu dùng nhất(5).

2.3. Phương pháp lây mẫu. Ngẫu nhiên thuận tiện.

2.4. Tiêu chí chọn mẫu. Người tiêu dùng tại thành phố Hồ Chí Minh đã từng sử dụng mỹ phẩm chăm sóc da và tự quyết định việc sử dụng mỹ phẩm chăm sóc da

2.5. Xử lý dữ liệu. Dữ liệu thu thâp được được xử lý với phần mềm MS Excel 2016 và SPSS 22.0

\section{KẾT QUẢ NGHIÊN CỨU}

3.1. Xây dựng hồ sơ chứa các thuộc tính mỹ phẩm chăm sóc da được người tiêu dùng tại thành phố Hồ Chí Minh ưu tiên lựa chọn. Dựa trên kết quả khảo sát trên 429 người tiêu dùng khắp cả nước của tạp chí $Q \& M E^{(6)}$, sau đó tiến hành phỏng vấn 6 chuyên gia và khảo sát thử 15 dược sĩ là học viên sau đại học có sử dụng mỹ phẩm, nghiên cứu sơ bộ xác định được bộ hồ sơ ban đầu gồm 9 thuộc tính và 52 mức thuộc tính.

Từ các mức thuộc tính xác định ở giai đoạn 1 , 
nghiên cứu tiếp tục tiến hành khảo sát để đánh giá mức độ yêu thích của người tiêu dùng tại TP.HCM đối với mỗi mức đô thuộc tính. Khảo sát được tiến hành trên 115 người tiêu dùng và thu về 113 phiếu hợp lệ.

Phiếu khảo sát giai đoạn 2 dùng thang đo 5 mức, khi đó:

Giá trị khoảng cách $=$ (Giá trị tối đa - Giá trị tối thiểu) $/ \mathrm{n}=(5-1) / 5=0,8$
Ý nghĩa các mức như sau:

1,00 - 1,80: Rất không quan tâm/Rất không quan trọng

1,81-2,60: Không quan tâm/Không quan trọng

2,61 - 3,40: Bình thường/ Trung bình

3,41 - 4,20: Quan tâm/ Quan trọng

4,21 - 5,00: Rất quan tâm/ Rất quan trong

Kết quả khảo sát được rút gọn và thể hiện ở Bảng 1 .

Bảng 1. Các mức thuộc tính được rút gọn từ kêt quả khảo sát giai đoạn 2

\begin{tabular}{|c|c|c|c|}
\hline Thuộc tính & Mức thuộc tính & $\begin{array}{c}\text { Điếm } \\
\text { số }\end{array}$ & $\begin{array}{l}\text { Mức độ yêu } \\
\text { thích }\end{array}$ \\
\hline \multirow{4}{*}{ Xuất xứ } & Hàn Quốc & 3,69 & Quan trong \\
\hline & Nhật Bản & 3,11 & Bình thường \\
\hline & Mỹ & 2,97 & Bình thường \\
\hline & Pháp & 2,97 & Bình thường \\
\hline \multirow{4}{*}{ Thành phần } & Thiên nhiên & 4,06 & Quan trong \\
\hline & Chiết xuất từ thảo dược & 3,50 & Quan trọng \\
\hline & Dân xuất vitamin & 3,14 & Bình thường \\
\hline & Chiết xuất từ khoáng chất & 2,65 & Bình thường \\
\hline \multirow{3}{*}{ Phân phối } & Cửa hàng riêng của từng thương hiệu & 3,08 & Bình thường \\
\hline & Cửa hàng mỹ phấm có bán nhiêu thương hiệu & 2,88 & Bình thường \\
\hline & Xách tay từ nước ngoài & 2,85 & Bình thường \\
\hline \multirow{3}{*}{ Dạng bào chế } & Dạng gel & 3,4 & Quan trọng \\
\hline & Dạng kem & 3,04 & Bình thường \\
\hline & Dang lotion & 2,87 & Bình thường \\
\hline \multirow{5}{*}{ Công dụng } & Dưỡng ấm & 3,72 & Quan trọng \\
\hline & Làm sạch & 3,72 & Quan trong \\
\hline & Trị mụn & 3,27 & Bình thường \\
\hline & Dưỡng trắng & 3,26 & Bình thường \\
\hline & Chống lão hóa & 3,17 & Bình thường \\
\hline \multirow{4}{*}{ An toàn } & Không gây kích ứng/tốn thương da & 4,25 & Rất quan trọng \\
\hline & Cảm giác nhẹ dịu khi sử dụng & 4,09 & Quan trọng \\
\hline & Không có mùi khó chịu & 3,53 & Quan trọng \\
\hline & Không chứa corticoid & 3,44 & Quan trong \\
\hline Chương trình khuyến mãi & Giảm giá & 3,44 & Quan trong \\
\hline \multirow{2}{*}{ Tư vấn, đánh giá } & Bạn bè, người thân & 3,73 & Quan trong \\
\hline & Nhân viên y tế & 2,69 & Bình thường \\
\hline
\end{tabular}

Các thuộc tính này được chia làm 2 nhóm chính là Nhóm thuộc tính được ứng dụng trong sản xuất và Nhóm thuộc tính được ứng dụng trong xây dựng chiến lược Marketing khi tung sản phẩm ra thị trường.

Vì số lượng thuộc tính đầu vào của phương pháp phân tích kết hợp tối đa chỉ nên $5-6$ thuộc tính, bên cạnh đó các thuộc tính ứng dụng trong sản xuất có tính cần thiết hơn để cho ra đời được 1 mỹ phẩm chăm sóc da kỳ vọng. Do đó nhóm thuộc tính được ứng dụng trong sản xuất mỹ phẩm chăm sóc da (xuất xứ, thành phần, dạng bào chế, công dụng, an toàn và giá) được chon để tiến hành phân tích kết hợp ở giai đoạn 3. Như vậy có 6 thuộc tính và 23 mức thuộc tính đưa vào khảo sát giai đoạn 3 .

Sử dụng SPSS 22 để chay thiết kể trực giao, từ 6 thuộc tính và mỗi thuộc tính có từ $3-5$ mức thuộc tính, danh sách hồ sơ sản phẩm đã rút gọn từ 2.880 về 25 hồ sơ được thể hiện ở Bảng 2.

Bảng 2. Danh sách hồ sơ sản phẩm rút gọn bằng thiết kế trực giao.

\begin{tabular}{|c|c|c|c|c|c|c|}
\hline Hồ sơ & Xuất xứ & Thành phân & $\begin{array}{c}\text { Dạng bào } \\
\text { chế }\end{array}$ & Công dụng & An toàn & $\begin{array}{c}\text { Giá } \\
\text { (ngàn đồng) }\end{array}$ \\
\hline 1 & Hàn Quốc & Thảo dược & Kem & Trị mụn & Không mùi & $700-<900$ \\
\hline 2 & Nhật & Thiên nhiên & Gel & Trị mụn & Nhẹ dịu & $300-<500$ \\
\hline
\end{tabular}




\begin{tabular}{|c|c|c|c|c|c|c|}
\hline 3 & Hoa Kỳ & Thiên nhiên & Gel & Dưỡng ẩm & Không mùi & $500-<700$ \\
\hline 4 & Pháp & Thảo dược & Gel & Làm sạch & Không corticoid & $300-<500$ \\
\hline 5 & Hàn Quốc & Thiên nhiên & Lotion & Làm sạch & Nhe diu & $500-<700$ \\
\hline 6 & Pháp & Khoáng chất & Gel & Chống lão hóa & Không mùi & $500-<700$ \\
\hline 7 & Hàn Quốc & Vitamin & Gel & Dưỡng trắng & Không corticoid & $500-<700$ \\
\hline 8 & Nhật & Khoáng chất & Gel & Dưỡng trắng & Nhe dịu & $700-<900$ \\
\hline 9 & Hàn Quốc & Vitamin & Gel & Trị mụn & Không kích ứng & $500-<700$ \\
\hline 10 & Nhật & Vitamin & Kem & Làm sạch & Khô̂ng mùi & $300-<500$ \\
\hline 11 & Hàn Quốc & Thảo dược & Gel & Chống lão hóa & Nhẹ dị & $300-<500$ \\
\hline 12 & Nhật & Thảo dược & Lotion & Chống lão hóa & Không kích ứng & $500-<700$ \\
\hline 13 & Hàn Quốc & Khoáng chất & Kem & Dưỡng ấm & Không kích ứng & $300-<500$ \\
\hline 14 & Hoa Kỳ & Thảo dược & Gel & Làm sạch & Không kích ứng & $700-<900$ \\
\hline 15 & Hàn Quốc & Thảo dược & Lotion & Dưỡng trắng & Không mùi & $300-<500$ \\
\hline 16 & Hoa Kỳ & Khoáng chất & Lotion & Trị mụn & Không corticoid & $300-<500$ \\
\hline 17 & Pháp & Thảo dược & Kem & Trị mụn & Nhe dịu & $500-<700$ \\
\hline 18 & Pháp & Vitamin & Lotion & Dưỡng Âm & Nhẹ dịu & $700-<900$ \\
\hline 19 & Hoa Kỳ & Thảo dược & Kem & Dưỡng trắng & Nhẹ dịu & $500-<700$ \\
\hline 20 & Hoa Kỳ & Vitamin & Kem & Chống lão hóa & Nhẹ dịu & $300-<500$ \\
\hline 21 & Nhât & Thảo dươc & Kem & Dưỡng ẩm & Không corticoid & $500-<700$ \\
\hline 22 & Hàn Quốc & Thảo dược & Gel & Dưỡng ấm & Nhe diu & $300-<500$ \\
\hline 23 & Hàn Quốc & Khoáng chất & Kem & sach & Nhe diu & $500-<700$ \\
\hline 24 & Pháp & Thiên nhiên & Kem & Dưỡng trắng & Không kích ứng & $300-<500$ \\
\hline 25 & Hàn Quốc & Thiên nhiên & Kem & Chống lão hóa & Không corticoid & $700-<900$ \\
\hline
\end{tabular}

3.2. Hồ sơ mỹ phẩm chăm sóc da được người tiêu dùng tại thành phố Hồ Chí Minh yêu thích nhất. Từ nội dung 2 có 6 thuộc tính và 23 mức thuộc tính, trong đó thuộc tính công dụng có 5 mức thuộc tính (cao nhất) như vậy cõ mẫu cần cho phân tích kết hợp nằm trong khoảng từ $(23-6+1) \times 5=90$ cho đến $(23-6+1) \times$ $10=180$, tuy nhiên theo công thức tính mẫu cho độ tin cậy 95\% (tương đương mức ý nghĩa $a=$ $0,05)$ thì cõ mẫu tối thiểu là 385 người tiêu dùng, do đó để tăng tính tin cậy, tính đại diện cho cõ mẫu, giai đoạn 3 của nghiên cứu được tiến hành khảo sát trên 500 người tiêu dùng.

Bảng 3. Mô tả cỡ mẫu khảo sát giai đoạn 3

\begin{tabular}{|c|c|c|}
\hline Biến mô tả & $\begin{array}{c}\text { Tần } \\
\text { số }\end{array}$ & $\begin{array}{l}\text { Phần } \\
\text { trăm }\end{array}$ \\
\hline Giới tính: Nữ & 355 & $76 \%$ \\
\hline Nam & 109 & $24 \%$ \\
\hline $23-30$ & 247 & $53 \%$ \\
\hline $31-40$ & 120 & $26 \%$ \\
\hline $15-22$ & 85 & $19 \%$ \\
\hline$>40$ & 12 & $3 \%$ \\
\hline \multicolumn{3}{|l|}{ Trình độ học vấn } \\
\hline Phố thông & 224 & $48,3 \%$ \\
\hline Đại học & 206 & $44,4 \%$ \\
\hline Cao đắng & 32 & $6,9 \%$ \\
\hline Thạc sĩ & 2 & $0,4 \%$ \\
\hline \multicolumn{3}{|c|}{ Thu nhập (triệu VND/tháng) } \\
\hline $5-7$ triệu & 159 & $35 \%$ \\
\hline 7 - 13 triệu & 135 & $29 \%$ \\
\hline
\end{tabular}

\begin{tabular}{|c|c|c|}
\hline 13 - 20 triệu & 48 & $10 \%$ \\
\hline$<3$ triệu & 46 & $10 \%$ \\
\hline $3-5$ triệu & 31 & $7 \%$ \\
\hline Chưa có & 29 & $6 \%$ \\
\hline$>20$ triệu & 12 & $3 \%$ \\
\hline \multicolumn{3}{|l|}{ Thói quen chăm sóc da } \\
\hline 1 lần 1 ngày & 158 & $33 \%$ \\
\hline 2 lần 1 ngày & 83 & $17 \%$ \\
\hline Không chăm sóc da hằng ngày & 234 & $49 \%$ \\
\hline \multicolumn{3}{|c|}{ Chi tiêu cho mỹ phấm chăm sóc da } \\
\hline $100-300$ & 157 & $34 \%$ \\
\hline $300-500$ & 122 & $27 \%$ \\
\hline$<100$ ngàn & 77 & $17 \%$ \\
\hline $500-700$ & 60 & $13 \%$ \\
\hline $700-900$ & 27 & $6 \%$ \\
\hline$>900$ & 16 & $3 \%$ \\
\hline
\end{tabular}

Từ dữ liệu thu được, tính toán tầm quan trọng các mức độ thuộc tính và điểm số tieên ích của các mức thuộc tính. Kết quả được thể hiện ở Bảng 4.

Bảng 4. Điểm số tiện ích của các mức thuộc tính và giá tri quan trọng của các thuộc tính

\begin{tabular}{|c|c|c|c|c|}
\hline & Điểm Số & ện ích & & $\begin{array}{l}\text { Giá trị } \\
\text { quaan }\end{array}$ \\
\hline & & $\begin{array}{l}\text { Điếm } \\
\text { số }\end{array}$ & $\begin{array}{l}\text { Độ lệ̂̉ch } \\
\text { chuẩn }\end{array}$ & \\
\hline & Hàn Quốc &,- 167 &, 096 & \\
\hline Xuất & Hoa Kỳ & 126 &, 119 & \\
\hline Xứ & Nhật &, 024 & 119 & 16,774 \\
\hline & Pháp & ,017 & ,119 & \\
\hline
\end{tabular}




\begin{tabular}{|c|c|c|c|c|}
\hline \multirow{4}{*}{$\begin{array}{l}\text { Thành } \\
\text { Phần }\end{array}$} & $\begin{array}{l}\text { Chiết xuất } \\
\text { thảo dược }\end{array}$ &,- 036 & 096 & \multirow{4}{*}{4,777} \\
\hline & Khoáng chất &,- 041 & ,119 & \\
\hline & Vitamin &, 035 & 119 & \\
\hline & Thiên nhiên & ,042 & 119 & \\
\hline \multirow{3}{*}{$\begin{array}{l}\text { Dạng } \\
\text { Bào Chê }\end{array}$} & Gel &,- 176 & ,087 & \multirow{3}{*}{19,285} \\
\hline & Kem & 161 & 087 & \\
\hline & Lotion & 015 & 104 & \\
\hline \multirow{5}{*}{$\begin{array}{l}\text { Công } \\
\text { Dụng }\end{array}$} & $\begin{array}{c}\text { Chống lão } \\
\text { hóa }\end{array}$ & 250 & 125 & \multirow{5}{*}{30,353} \\
\hline & Dưỡng Âm & ,049 &, 125 & \\
\hline & Dưỡng Trắng & 081 &, 125 & \\
\hline & Làm sạch &,- 099 & 125 & \\
\hline & Trị mụn &,- 281 & 125 & \\
\hline \multirow{4}{*}{ An Toàn } & $\begin{array}{l}\text { Cảm giác } \\
\text { nhe diu }\end{array}$ &,- 024 & 096 & \multirow{4}{*}{18,616} \\
\hline & $\begin{array}{l}\text { Không chứa } \\
\text { corticoid }\end{array}$ & 202 & 119 & \\
\hline & Không mùi &,- 124 & ,119 & \\
\hline & $\begin{array}{l}\text { Không kích } \\
\text { ứng }\end{array}$ &,- 054 & 119 & \\
\hline \multirow{3}{*}{ Giá } & $300-<500$ & ,072 & ,087 & \multirow{3}{*}{10,195} \\
\hline & $500-<700$ &,- 107 & ,087 & \\
\hline & $700-<900$ &, 035 & 104 & \\
\hline \multicolumn{2}{|r|}{ Hằng số } & 13,021 & ,077 & \\
\hline
\end{tabular}

Trong đó tầm quan trọng của các mức độ thuộc tính giảm dân từ thuộc tính Công dụng (điểm số quan trong 30.353) đến thuộc tính Dạng bào chế (điểm số quan trọng 19.285) đến thuộc tính An toàn (điểm số quan trọng 18.616) sau đó tới thuộc tính Xuất xứ (điểm số quan trọng là 16.774), tiếp theo là thuộc tính Giá cả (điểm số quan trọng 10.195) và cuối cùng là thuộc tính Thành phần (điểm số quan trọng 4.777).

Từ kết quả phân tích kêt hợp cho thấy MPCSD kỳ vọng được người tiêu dùng tại thành phố Hồ Chí Minh yêu thích nhất là MPCSD có xuất xứ từ Hoa Kỳ, thành phần từ Thiên nhiên, có công dụng Chống lão hóa, được bào chế dưới dạng Kem, không chứa Corticoid và có giá bán giao động từ 300.000 đồng đến dưới 500.000 đồng. Mỹ phẩm kỳ vọng có điểm số tiện ích tổng: $0,126+0,042+0,161+0,25+0,202+$ $0,072+13,021=13,874$.

\section{BÀN LUÂN}

Có sự chênh lệch lớn giữa tỷ lệ khảo sát thành cồng nữ và nam, nguyên nhân là do khi được mời tham gia khảo sát thị trường về mỹ phẩm chăm sóc da, đa số nam giới từ chối với lý do không sử dụng mỹ phẩm, không am hiểu về mỹ phẩm nên không tham gia khảo sát.

Về phân bố độ tuổi và công việc của cỡ mẫu, có sự chênh lệch tỷ lệ giữa các nhóm tuổi và nghề nghiệp nhưng đối với khảo sát thị trường về mỹ phẩm chăm sóc da, sự chênh lệch này có thể chấp nhận được [1].

Địa điểm khảo sát và thời gian khảo sát được lựa chon cũng đem lại các ưu điểm như sau: địa điểm khảo sát là trung tâm thương mại không chỉ có người tiêu dùng lân cận mà còn thu hút được những người tiêu dùng ở quận, huyện khác tham gia mua sắm, qua đó tăng tính đải diên của cỡ mẫu. Thời gian khảo sát là giờ hành chính các ngày trong tuần, người tiêu dùng có mặt ở trung tâm thương mại trong thời gian này là những người có thời gian, việc này giúp gia tăng tỷ lệ khảo sát thành công [2].

Điểm mới của nghiên cứu so với các nghiên cứu về mỹ phẩm đã công bố trong nước là sử dụng phương pháp phân tích kết hợp cho đối tượng nghiên cứu là các thuộc tính và mức độ thuộc tính của MPCSD.

Nghiên cứu vẫn còn một số điểm hạn chế như sau: Cõ̃ mẫu tuy đã đủ điều kiện tiến hành các phương pháp phân tích xử lý sổ liêu nhưng so với dân số trên 9 triệu người tại thành phố Hồ Chí Minh thì có phần chưa tương xứng và chưa có tính đại diện cho toàn dân số. Công cụ khảo sát được chọn là phiếu khảo sát, đây chưa phải là công cụ tốt nhất của phương pháp phân tích kết hợp.

Trên thực tễ, để đưa sản phẩm ra thị trường nhà cung cấp sẽ có những chiến lược khác nhau cho từng đối tượng dân số khác nhau. Với mỗi đối tượng, một hoặc một vài loại sản phẩm thích hợp được nhà cung cấp đưa ra để phục vụ đối tượng này. Để làm được điều đó, trước hết cần phải quan tâm đến sự khác nhau trong cách đánh giá của các đối tượng khác nhau trên từng thuộc tính và mức độ của MPCSD. Kết quả PTKH cho người tiêu dùng nam và nữ có sự khác biệt: Nam giới quan tâm tới thuộc tính Công dụng nhất khi mua MPCSD trong khi nữ giới lại quan tâm tới thuộc tính Xuất xứ nhất. Nam giới tại thành phố Hồ Chí Minh ưa thích sản phẩm có chứa vitamin, dạng lotion, có tác dụng chống lão hóa trong khi nữ giới lại ưa thích sản phẩm chứa khoáng chất, dạng kem, có tác dung trị mun [4]. Các thuộc tính còn lại cả 2 giới đều yêu thích các mức độ tương tự nhau. Về độ tuổi, các MPCSD có chứa thành phần từ thiên nhiên, không chứa corticoid phù hợp với mọi lứa tuổi, khách hàng khảo sát từ 23-30 tuổi ưa thích MPCSD từ Hoa Kỳ, dạng kem, có tác dụng chống lão hóa và giá từ 700-900 nghìn VND trong khi khách hang khảo sát từ 31-40 tuổi lại ưa thích sản phẩm có xuất xứ từ Hàn Quốc, dạng lotion, có công dụng trị mun và giá từ 300-500 ngàn vnd. Đối với thu 
nhập, nhóm thu nhập dưới 5 triệu/tháng ưa thích MPCSD có xuất xứ từ Hàn Quốc, dạng lotion, có tác dụng dưỡng trắng và làm sạch, ở nhóm có thu nhập 5-13 triệu/tháng sẽ ưu tiên các MPCSD có xuất xứ Pháp, có tác dụng chống lão hóa. Các thuộc tính khác ở hai nhóm không có khác biệt quá lớn [6].

Kết quả khảo sát sau khi được phân tích và kiểm định cho thấy có sự khác nhau về MPCSD kỳ vọng giữa các nhóm đối tượng. Vì thế, nhà cung cấp muốn nhắm vào đối tượng cụ thể phải lựa chọn sản phẩm phù hợp để phát triển kế hoạch sản xuất và đạt hiệu quả kinh doanh cao nhất.

\section{KẾT LUÂN}

Trong bối cảnh tiềm năng kinh doanh MPCSD ngày càng lớn, cơ hội đầu từ và phát triển cho các doanh nghiệp cũng càng được mở rộng. Tuy nhiên để có thể lên kế hoạch sản xuất và phát triển sản phẩm là MPCSD, các doanh nghiệp phải nắm bắt rõ được những kỳ vọng về MPCSD của người tiêu dùng. Nghiên cứu đã cung cấp cái nhìn khái quát nhất về một MPCSD kỳ vọng của người tiêu dùng TPHCM, qua đó giúp doanh nghiệp có cái nhìn khách quan về phương hướng phát triển sản phẩm. Bên cạnh đó, nghiên cứu cũng cung cấp thêm thông tin về xu hướng sử dụng MPCSD của người tiêu dùng theo giới tính, độ tuổi, mức thu nhập để các nhà quản lý có cái nhìn sâu hơn về nhu cầu của từng nhóm người tiêu dùng.

\section{TÀI LIẸU THAM KHẢO}

1. Maslow, A.H. (1943). "A theory of human motivation". Psychological Review, 50 (4): 370-96.

2. Ban Chỉ đạo Tổng điêuu tra dân số và nhà ở trung ương (2019), Tổng điêuu tra dân số và nhà ở năm 2019, Bộ Kế hoạch và Đâuu tư

3. Statista (2019), Cosmetic in Vietnam, https:// www.statista.com/ outlook/70010000/ 127/cosmetics/vietnam\#market-arpu, [Truy cập ngày 16/11/2019]

4. Vietnamnet Global (2019), How big is Vietnam's cosmetics market?, https:// vietnamnet.vn/en/business/how-biq-is-vietnam-scosmetics-market-529857.html, [truy cập ngày 15/11/2019].

5. Green P. and Srinivasan V. (1978), "Conjoint analysis in consumer research: issue and outlook", J.consum. Res. 5 (2), pp. 103-123.

6. Asia Plus Inc (2019), Vietnam Cosmetics Market 2019, Q\&ME, pp. 36.

\section{NGHIÊN CỨU THAY ĐỔI GIỌNG NÓI Ở BÊ̂NH NHÂN SAU CẮT AMIĐAN}

\section{TÓM TẮT.}

Phẫu thuật cắt Amidan là một trong những loại phẫu thuật phổ biến nhất trong tai mũi họng, chiếm khoảng 2,3\% -26,9\% tổng số các ca phẫu thuật tai mũi họng. Việc cắt bỏ amiđan ít nhiêuu làm thay đổi kích thước khoang họng và tác động đến các giai đoạn hình thành giọng nói trong đó có bộ phận cấu âm và cộng hưởng. Trên thế giới, việc nghiên cứu về sự thay đổi giọng nói sau cắt amiđan mới bắt đầu được nghiên cứu từ năm 1994. Từ đó đến nay, một số nghiên cứu đã được thực hiện cho thấy chất lượng giọng nói đều có thay đổi ở các mức độ khác nhau sau phẫu thuật cắt Amiđan. Nghiên cứu được tiến hành trên 35 bệnh nhân được cắt Amiđan tại Bệnh viện Tai Mũi Họng trung ương, được phân tích giọng trước và sau cắt Amiđan bằng chướng trình phân tích

${ }^{1}$ Phòng khám CK Tai mũi họng 103 Thành Công

2Trường Đại học Y Hà Nôi,

${ }^{3}$ Bênh viện Đại học Y Hà Nội

Chịu trách nhiệm chính: Lề Văn Huyên

Email: levanhuyen1983@gmail.com

Ngày nhân bài: 9.3.2021

Ngày phản biên khoa học: 27.4.2021

Ngày duyệt bài: 11.5.2021

\section{Lê Văn Huyên', Phạm Thị Bích Đào ${ }^{2,3}$, Trần Văn Tâm ${ }^{3}$, Mai Thị Mai Phương ${ }^{4}$}

âm PRAAT. Kết quả:Tuổi: 6- 18 tuổi: 62,3\%, trên 1825 tuổi: 23,6\%, trên 25 - 55 tuổi: 11,3\%; trên 55: $2,8 \%$. Nam $56,2 \%$, nữ: 43,8\%.lý do cắt amidan: viêm trên 07 lần/ năm 54,7\%, do ngủ ngáy 19,3\%, do hơi thở hôi $9,7 \%$, do vướng họng 16,3\%. Phân đô amidan: I $(21,9 \%)$, II $(31,1 \%)$, III $(34,3 \%)$, IV $(12,7 \%)$. Chất giong:Phát âm nguyên âm trước khi cắt Amiđan: âm trung tính (chỉ số Shimmer 3,251, Jitter 0,984\%, HNR 18,003), sau khi cắt Amiđan: âm trung tính (chỉ số Shimmer 3,336, Jitter 0,965, HNR 19,115),; Trước phẫu thuât cắt Amiđan, các phu âm mũi, mặt lưỡi, tắc, gốc lưỡi, vô thanh; bật hơi; có các chi số về chất thanh: Shimmer, Jitter, HiNR trong giới hạn bình thường; Phụ âm xát gốc lưỡi vô thanh: Shimmer:3,991, Jitter: 1,231, HNR: 21,002; xát thanh hâu: Shimmer: 3,921, Jitter: 1,312, HNR: 21,004; Sau cắt amiđan: các phụ âm mũi, tắc, gốc lưỡi, vô thanh; xát gốc lưỡi vô thanh; xát thanh hầu; có các chỉ số về chất thanh: Shimmer, Jitter, HNR trong giới hạn bình thường; Phụ âm: mặt lưỡi,Shimmer:3,892, Jitter: 1,114, HNR: 21,004;:bật hơi: Shimmer: 3,921, Jitter: 1,102, HNR: 20,006.Sau cắt Amiđan: nguyên âm: trung tính (Shimmer 25dB, Jitter 1,859\%, HNR 19,115). Các phụ âm mũi, tắc, gốc lưỡi, vô thanh; xát gốc lưỡi vô thanh; xát thanh hầu; có các chỉ số về chất thanh: Shimmer, Jitter, HNR trong giới hạn bình 